\title{
CONSIDERAÇÕES SOBRE ALGUNS PROCESSOS SISTÊMICOS E DISCURSIVOS DA MARCA DE PRODUTO ${ }^{1}$
}

\section{Considerations about a few sistemic and discursive processes of product branding}

\author{
Jean Charles Jacques Zozzoli ${ }^{2}$
}

\begin{abstract}
Resumo
O artigo apresenta parte de um estudo sobre a economia semiótica da marca realizado pelo Autor. No quadro da semiótica da Escola de Paris, examina as estruturas discursivas que organizam, num nível superficial, a colocação em discurso das estruturas narrativas da marca. Considerando as condições de actorialização e aspectualização, evidencia subuniversos do discurso da marca e fornece uma tipologia dos sujeitos e relações actanciais que podem ser assumidas.
\end{abstract}

Palavras-chave: marca, semiótica, programas narrativos.

\begin{abstract}
The article presents part of a study on the semiotic economy of the brand performed by the author. Relying on the semiotics of the School of Paris, examines the discursive structures that organize the discursivization ("mise en discours") of the narrative structures of the brand in a superficial level. Considering the conditions of actorialization and aspectualization, shows sub-universes of brand discourse and supplies with a typology of subjects and actantial relations that can be taken.
\end{abstract}

Keywords: brand, semiotics, narrative program.

\section{Resumen}

El artículo presenta una parte de un estudio sobre la economía semiótica de la marca realizado por el autor. Basado en la semiótica de la Escuela de París, analiza las estructuras

\footnotetext{
${ }^{1}$ Os resultados de pesquisas apresentados neste artigo decorrem de estudos sobre a marca efetuados pelo Autor nas duas últimas décadas.

${ }^{2}$ Graduado em Propaganda e Marketing (Université de Franche-Comté -Besançon); Especialista em Lingüística e Comunicação (UFAL); Mestre em Multimeios (UNICAMP); Doutor em Ciências da Comunicação (USP). Professor Associado da Universidade Federal de Alagoas. Seus estudos inéditos sobre a mise en scène da marca lhe renderam o prêmio Intercom 94. Desenvolve atualmente pesquisas sobre Marca, Comunicação e Autopoiese. É também coordenador do núcleo de pesquisa Publicidade e Propaganda da Intercom. E-mail: jczoz@uol.com.br.
} 
discursivas que organizan, en un nivel superficial, la puesta en el discurso de las estructuras narrativas de la marca. Teniendo en cuenta las condiciones de actorialização y aspectualização, muestra sub-universos de discurso de la marca y ofrece una tipología de los sujetos y las relaciones actanciais que se pueden tomar.

Palabras-clave: marca, semiótica, programas narrativos.

\section{INTRODUÇÃO}

Este artigo se propõe a examinar alguns conceitos e valores do processo sociocultural que envolve a marca registrada e os cidadãos brasileiros como consumidores de produtos, serviços e denominações verbais e plásticas em suas relações diárias.

Num simulacro metodológico, recorre-se à Semiótica greimasiana clássica que estudou as formas lógicas da ação. A análise das diversas feições do discurso marcário ${ }^{3}$ e a significação que delas emana são, portanto, apreendidas aqui como cenas em que se desenrolam percursos narrativos com encadeamento de programas de competência e realização. A análise permite delinear, tipologicamente, os perfis dos sujeitos e dispositivos basilares envolvidos, variáveis em função das situações.

Por considerar as manifestações lingüísticas da marca e aquelas a seu respeito sistemas incorporadores e refletores de ações e movimentos sociais, o intuito dessa abordagem consiste, num primeiro tempo, numa tentativa de mapeamento simples, em "balizar" os diversos significados da marca em relação a seus contextos, para, a partir dessas referências, contribuir para situar e definir, sem parcelá-la, a significação da marca.

Não são, pois, os signos, nem sua produção técnica, nem sua relação com a "realidade diária" e os objetos referentes, o cerne da reflexão desenvolvida neste artigo, mas as formas significantes, os sistemas de relações que fazem da marca, ou de qualquer texto marcário, um objeto de sentido. Como essas formas se organizam para que a marca signifique? Defende-se que a teoria semiótica do discurso que simula o percurso gerativo pode ser de grande valor explicativo, tanto na apreensão da significação da marca, como na apreensão de sua expressão verbal e plástica, mesmo sem dar conta, neste estudo, da tensividade presente na economia da significação, uma vez que, por trabalhar com modalidades genéricas, não se faz aqui um levantamento cinético dos percursos, nem se consideram efeitos de sentido próprios da Semiótica das paixões.

A diversidade das concepções da marca que se encontram em macro-textos nos

\footnotetext{
${ }^{3}$ Neologismo referente à marca retirado de Bittencourt, 1991.
} 
livros e manuais tecnológicos (meta-linguagem), nas produções diárias (atos de linguagem)

e seu resumo em dicionários, no que diz respeito ao saber e fazer cotidianos dos fabricantes, revendedores, profissionais adjuvantes, e consumidores, é observável em textos não só lingüísticos (obras a respeito) como sincréticos (ações multimidiáticas, jurídicas, administrativas, socioculturais, dentre outras que remetem à produção, à circulação, à troca e ao consumo de bens simbólicos nos níveis tangível e intangível compra/adesão, marcação física/marcação psíquica).

Determina-se, pois, um campo de análise da marca, dentro do qual se inscrevem marcos do contexto econômico, social, político e cultural, incluindo-se ainda a historicidade da situação, lugar de uma socialidade intersubjetiva, através dos próprios condicionamentos culturais.

Essa reflexão consiste, então, entre outros assuntos, na análise de código(s) cultural(ais) de produção e percepção simbólica que se fazem presentes na própria constituição da(s) emissão(ões) da marca e na(s) sua(s) reelaboração(ões), quando da recepção por cada segmento social. Trata-se de uma investigação que se situa no domínio dos fenômenos da cultura e da comunicação de massa, por focalizar o estudo do processo de produção, circulação, troca e consumo de bens tangíveis, mascarados sob a relação de produção, circulação, troca e consumo de bens simbólicos, dos quais muitos pertencem ao imaginário.

Precisamente por causa desse fetichismo, os dados a serem analisados correm o risco de serem presos às ilusões e inversões ideológicas das representações imediatas. Eles necessitam, portanto, ser interpretados, isto é, mediatizados pela teoria.

Assim, recorre-se ao método de análise do discurso do qual fala Pais (1993: 6035). A Sociossemiótica é um ramo da Semiótica que estuda discursos cujo enunciador e o enunciatário são necessariamente coletivos, um segmento da sociedade ou a sociedade inteira. A axiologia que neles se detecta é estreitamente relacionada ao seu modo de existência e produção, como também ao seu estatuto sociossemiótico e a sua estrutura super-profunda de conceptualização. Os estudos de seus aspectos, aliados ao conceito de macrossemiótica, permitem analisar a Semiótica da cultura - entendida aqui em seu sentido antropológico - numa outra perspectiva, uma vez que os sistemas de significação e seus discursos em operação, numa mesma comunidade sócio-lingüísticocultural, produzem recortes culturais coerentes e compatíveis, que sustentam uma visão do mundo também coerente e uma ideologia subjacente a essa cultura e seus discursos. 
"Le monde "référentiel", ou le monde sémiotiquement construit, étant soutenu par tous les systèmes sémiotiques et leurs discours qui opèrent à l'intérieur d'une communauté linguistique et socioculturelle donnée, nous appelons cet ensemble la macrosémiotique d'une culture. D'autre part, tous les systèmes de signification sont en constant fonctionnement-dans la vie sociale -et changement-sur l'axe de l'histoire; par conséquent, ils sont tous spatialement délimités et historiquement déterminés. De cette manière il nous semble possible d'arriver à une meilleure compréhension de la nature, de la structure et du fonctionnement des langues naturelles e de leurs discours, dans le cadre élargi de l'aptitude sémiotique de l'homme." (Pais 1993 : 688).

A marca, que assume configurações não só comerciais, mas de outros tipos, como heráldicas, folclóricas, biológicas, etc., como enunciado pressupõe uma instância da enunciação, isto é de produção do sentido, que pode ser representada num eixo de comunicação entre o enunciador e o enunciatário. Essa comunicação pressupõe um saber do enunciador sobre o saber do enunciatário e reciprocamente um saber do enunciatário sobre o saber do enunciador.

Nos níveis da sintaxe e da semântica narrativas, revelam-se vários programas narrativos e seleção e atualização de valores específicos, que permitem uma aproximação do percurso gerativo ${ }^{4}$ da produção da enunciação de codificação e decodificação marcária.

\section{ALGUMAS REFLEXÕES SOBRE A ECONOMIA SEMIÓTICA DA MARCA}

É possível encontrar discursos que manifestam o conceito da marcação do produto e sustentam, em suas axiologias, hierarquias e oposições fundamentais de valores modais. Com efeito, no caso da marca de produto, encontram-se vários tipos de programas narrativos, isto é de um fazer ser do sujeito, ou dito de outra maneira, de um "chamamento à existência semiótica de um novo “estado de coisa"” (Greimas \& Courtès 1983: 435; 1986: 177-9), seja esse estado resultado de uma transformação estacionária ou dinâmica.

Apresentam-se, a seguir, os que parecem mais usuais, levando em conta:

-a competência do sujeito (o que faz ser) para reconhecimento de seu desempenho (o fazer ser), na circulação de objetos de valor;

-a relação sujeito/objeto, que, como percurso da ação, mostra-se ser uma relação de meta, de procura, criando a tensão necessária ao engate da narrativa;

-a relação destinador/destinatário, ou percurso da manipulação, que é uma relação

\footnotetext{
${ }^{4}$ Estuda-se só a marcação de produtos (bens, serviços, idéias, candidatos, instituições...), não podendo, portanto, afirmar se o percurso gerativo revela-se idêntico no caso de outras marcações. Porém, a noção de produto como resultado de uma produção permanece em sua essência a mesma, qualquer que seja o tipo de produto.
} 
de comunicação;

-a relação actancial adjuvante/oponente;

A narrativa é aqui considerada como uma circulação de objeto de valor entre sujeitos, onde cada estado ou etapa lógica é definido ou por uma conjunção ou por uma disjunção e onde o sujeito de estado disjunto ou conjunto é ou não é o sujeito que opera a conjunção ou a disjunção.

\subsection{Do percurso gerativo da enunciação marcária}

Para estudar o percurso canônico do percurso gerativo da enunciação marcária, consideraram-se as estruturas discursivas que organizam, num nível superficial, a colocação em discurso das estruturas narrativas a partir da instância da enunciação, observando que as estruturas discursivas correspondem à mise en scène e à distribuição dos contextos (actorialização temporalização e espacialização - sintaxe discursiva) e à tematização e figurativização (semântica discursiva) e as estruturas sêmio-narrativas ao enredo no que tem de mais abstrato e essencial.

Além das estruturas discursivas apresentadas a seguir, chegou-se a estruturas sêmio-narrativas que, em seu nível mais abstrato, contêm a "instalação" das diferenças que fazem aparecer a significação, assim como as regras de percurso entre as posições estabelecidas. É a instância $a b$ quo do percurso gerativo. O quadrado (e posteriormente octógono) semiótico - proposto pelo autor deste artigo no que concerne à articulação da categoria marcado/não-marcado e apresentado em outros espaços (Zozzoli, 1994, 2002, por exemplo) - é uma representação do que acontece nesse nível. Num nível mais superficial dessas estruturas, as posições encontram-se convertidas em valor procurado pelos sujeitos (semântica narrativa) e nos programas e percursos narrativos (sintaxe narrativa de superfície).

\subsubsection{Programas narrativos, modalidades e universos de discurso marcários}

Ciente de que i) o conjunto dos discursos manifestados divide-se em subconjuntos de abrangência mais restrita, mais específica; ii) a eficácia relativa de um discurso depende da competência modal dos sujeitos enunciadores/enunciatários; iii) o saber/conhecimento e a competência conferem o poder; ao considerar as condições de actorialização e aspectualização associadas, é possível salientar os sub-universos seguintes no universo do 
discurso marcário:

1. discurso marcário dos fabricantes/revendedores,

2. discurso marcário dos consumidores,

3. discurso marcário dos publicitários/comunicadores,

4. discurso marcário dos programadores visual,

5. discurso marcário dos juristas,

6. discurso marcário dos administradores/mercadólogos,

7. discurso marcário dos skateholders (públicos internos e externos além dos citados nesta lista, por exemplo, funcionários, parceiros de negócio, acionistas, instituições públicas e organizações não-governamentais), e

8. discurso marcário da sociedade.

Obviamente, não se trata de fazer, nessa reflexão, um levantamento exaustivo. Os atores (com vários papéis actanciais) aqui presentes são os que mais intervêm na produção de discursos manifestados na contemporaneidade. Os discursos relativos à marcação em outras épocas e espaços sóciopolíticos, tais como a presença da marca nas sociedades antigas ou agrárias, na Idade Média, nos primórdios da Revolução Industrial ou até os anos cinqüenta, não foram considerados no quadro desse estudo.

Apresentam-se alguns programas narrativos referentes a esses sub-discursos no quadro 1.

\begin{tabular}{|l|l|l|l|}
\hline \multicolumn{4}{|c|}{ Considerando o percurso narrativo do sujeito, isto é, o percurso da ação, vê-se que: } \\
\hline em & $\begin{array}{l}\text { o sujeito de posse da } \\
\text { competência instaurada } \\
\text { pela sua posição }\end{array}$ & $\begin{array}{l}\text { investe a marca como objeto de valor } \\
\text { que confere pela sua natureza } \\
\text { relacional determinação de }\end{array}$ & $\begin{array}{l}\text { ao modalizar esse } \\
\text { objeto numa relação } \\
\text { predicativa de }\end{array}$ \\
\hline 1 & $\begin{array}{l}\text { fabricantes/reven- } \\
\text { dedores(visão de produtor) }\end{array}$ & $\begin{array}{l}\text {-garantir a procedência (não em termos } \\
\text { geográficos, mas em termos de quem } \\
\text { fabrica e /ou revende), em outros } \\
\end{array}$ & $\begin{array}{l}\text { fazer poder ser fazer } \\
\text { dever ser }\end{array}$ \\
& & $\begin{array}{l}\text {-controlar operações de distribuição, } \\
\text { logística, armanezamento e venda }\end{array}$ & poder fazer querer \\
& & & fazer \\
\hline
\end{tabular}

\footnotetext{
${ }^{5}$ Ou mais simplesmente, numa outra formulação: "busca na marca o valor que lhe permite...".

${ }^{6} \mathrm{Ou}$, ainda, dito de outra forma, identificar o fabricante, autenticar seus produtos, ser suporte de garantia.

${ }^{7}$ A origem etimológica de marca, marque, marca ou marchio... é a palavra germânica marka que significa "signo". Seu uso nas línguas latinas, aproximadamente no final do século XIV seria ligado ao direito de entrar, e no século XVI, à sinalização da propriedade e também ao estigma. Observa-se como esse "direito de entrar" aplica-se atualmente para as marcas de fabricante quanto à sua distribuição por meio do "direito" de ser referendado, isto é, de "entrar" (com a devida vendagem, e às vezes taxas) no mercado. Presentemente constata-se uma tendência de certas marcas de distribuidores (marcas de comércio e franchising) em querer
} 


\begin{tabular}{|c|c|c|c|}
\hline & & -garantia contra a pirataria & não poder não ser \\
\hline \multirow[t]{7}{*}{$2^{8}$} & \multirow[t]{7}{*}{ consumidores } & $\begin{array}{l}\text {-função de identificação (natureza da } \\
\text { oferta) }\end{array}$ & querer saber \\
\hline & & $\begin{array}{l}\text {-localização (percepção do leque de } \\
\text { possibilidades de ofertas) }\end{array}$ & saber ser \\
\hline & & $\begin{array}{l}\text {-garantia (promessa de compromisso } \\
\text { público de qualidade permanente) }\end{array}$ & saber ser \\
\hline & & $\begin{array}{l}\text {-praticidade (memória de vivência de } \\
\text { compra e consumo) }\end{array}$ & saber ser \\
\hline & & $\begin{array}{l}\text {-lúdica (prazer intelectual, } \\
\text { entretenimento) }\end{array}$ & poder ser \\
\hline & & $\begin{array}{l}\text {-personalização (situar-se em relação } \\
\text { ao seu ambiente social) }\end{array}$ & querer ser \\
\hline & & -personalização com uso ostentatório & (querer) fazer saber \\
\hline \multirow[t]{2}{*}{3} & \multirow[t]{2}{*}{$\begin{array}{l}\text { publicitários/ } \\
\text { comunicadores }\end{array}$} & $\begin{array}{l}\text {-suporte de imagem (criar diferença } \\
\text { entre produtos equivalentes) }\end{array}$ & $\begin{array}{l}\text { poder fazer ser querer } \\
\text { saber fazer }\end{array}$ \\
\hline & & $\begin{array}{l}\text {-representa não só o produto, mas a } \\
\text { empresa, todo o pessoal }\end{array}$ & fazer saber \\
\hline 4 & designers & -algo bonito e significativo & dever ser \\
\hline 5 & $\begin{array}{l}\text { juristas, legisladores, } \\
\text { advogados }\end{array}$ & -questão da anterioridade & $\begin{array}{l}\text { fazer ser saber ser fazer } \\
\text { saber }\end{array}$ \\
\hline 6 & mercadólogos & $\begin{array}{l}\text {-subsumir todas as determinações } \\
\text { anteriores }\end{array}$ & $\begin{array}{l}\text { querer poder fazer } \\
\text { saber querer poder } \\
\text { fazer ser }\end{array}$ \\
\hline \multirow[t]{2}{*}{7} & \multirow[t]{2}{*}{ skateholders } & -caracterizar relacionamentos & $\begin{array}{l}\text { saber ser/dever } \\
\text { ser/fazer saber fazer } \\
\text { saber saber fazer fazer } \\
\text { saber dever fazer } \\
\text { querer poder fazer } \\
\text { saber querer poder } \\
\text { fazer ser }\end{array}$ \\
\hline & & -abonar características e operações & $\begin{array}{l}\text { saber ser/dever } \\
\text { ser/fazer saber fazer } \\
\text { saber saber fazer fazer } \\
\text { saber dever fazer } \\
\text { querer poder fazer } \\
\text { saber querer poder } \\
\text { fazer ser }\end{array}$ \\
\hline \multirow[t]{2}{*}{8} & \multirow[t]{2}{*}{ sociedade } & -diferenciar (em sentido amplo) & $\begin{array}{l}\text { saber ser/dever } \\
\text { ser/fazer saber fazer } \\
\text { saber saber fazer fazer } \\
\text { saber dever fazer } \\
\text { querer poder fazer } \\
\text { saber querer poder } \\
\text { fazer ser }\end{array}$ \\
\hline & & -garantir (em sentido amplo) & $\begin{array}{l}\text { saber ser/dever } \\
\text { ser/fazer saber fazer } \\
\text { saber saber fazer fazer } \\
\text { saber dever fazer } \\
\text { querer poder fazer } \\
\text { saber querer poder } \\
\text { fazer ser }\end{array}$ \\
\hline
\end{tabular}

Quadro 1 - Alguns programas narrativos referentes a sub-discursos marcários.

A ordem de apresentação seguida não tem nenhum significado, nem cronológico,

gozar das prerrogativas das marcas de fabricantes, até em alguns casos com a pretensão de enfraquecer seu poder (caso das marcas próprias). O caso do licensing configura a locação de uma marca, sem que se haja produção de bens ou serviços, porém assemelha-se, uma vez firmado o contrato, à marca de produto. 
Considerações sobre alguns processos sistêmicos e discursivos da marca de produto de Jean Charles Jacques Zozzoli

nem de importância comercial, sócio-relacional, de poder, ou outra.

Em conclusão, destacam-se os valores de identificação, diferenciação e garantia e principalmente as combinatórias de modalidades complexas saber-ser, fazer-saber, deverser, fazer-saber, fazer-saber-saber-fazer, fazer-saber-dever-fazer, em suma, no mínimo fazer saber.

\subsubsection{Actantes e atores marcários}

Estabeleço, a seguir (ver quadro 2), alguns dos mais comuns exemplos de actância e suas relações com atores. Esses exemplos se dão concomitantemente e os sujeitos são complementares.

Destinatário
"consumidores"

Destinatário

"concorrência"

Sujeito

"concorrentes, piratas"

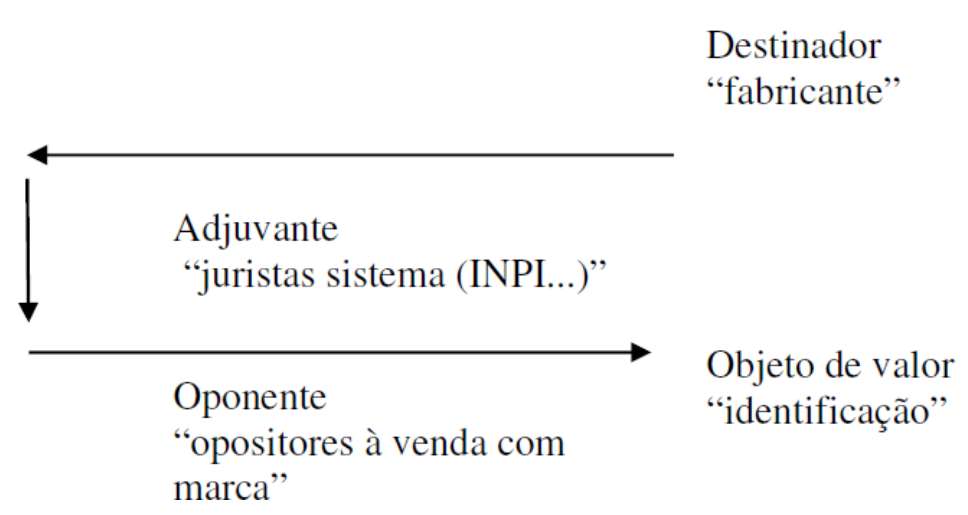

Destinador

"fabricante"

Adjuvante

"juristas sistema (INPI...)"

Oponente

marca"

${ }^{8}$ As relações da marca com os consumidores se dão na base de um contrato fiduciário. 
Destinatário

"revendedores"

Sujeito

"revendedores"

Destinatário

"sociedade"

Sujeito (um dos) "consumidores"

Destinatário "consumidores, revendedores"

Sujeito "consumidores, revendedores"
Destinador

"fabricante"
Adjuvante

"profissionais ligados à

marca"

Oponente

"concorrentes"

Objeto de valor

"identificacão, localização, garantia, personalização"

Destinador

"revendedor"
Objeto de valor

"(conferir à marca de distribuidor os valores da marca de fabricante), identificação, localização, garantia"

Destinador "publicitário"

Adjuvante

"distribuidores e outros

profissionais ligados à marca"

Oponente

"Organismos de defesa do

Objeto de valor

“identificação para

consumidor,

memorização das qualidades

opositores à venda com marca, intrínsecas e extrínsecas do

profissionais a serviço dos

concorrentes" 
Destinatário

"sociedade"

Sujeito

"todos"

Destinatário

"grupos societários"

Sujeito

"os indivíduos,

o próprio consumidor"
Destinador

"juristas"

Adjuvante

"defensores da venda com

marca"

Objeto de valor

"a marca é única"

Oponente

"opositores à venda com

marca"

Destinador

"consumidor"

\section{Adjuvante}

"publicitários e outros

profissionais a serviço da

marca

o grupo societário do

consumidor"

Objeto de valor

Oponente "personalização,

"adeptos do 'desligamento', integralização ao grupo" movimentos consumeristas"

Destinatário

"Indivíduos, grupos societários

A sociedade"
Destinador

"skateholders"
Sujeito (um dos)

"Indivíduos, grupos

Societários, todos"

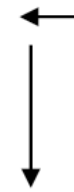

Adjuvante

"profissionais e grupos

envolvidos"

$\begin{array}{ll}\text { Oponente } & \text { Objeto de valor } \\ & \text { "engendramento de sistema de } \\ & \text { relacionamento" }\end{array}$

Quadro 2 - Focalização sinótica de alguns exemplos de actâncias e suas relações com atores, no que diz respeito à marca de produto.

\section{CONSIDERAÇÕES FINAIS}


$\mathrm{O}$ rol de actâncias e suas relações com atores, no que diz respeito à marca de produto é evidentemente incompleto. Mesmo assim, permite uma focalização sinótica abrangente de actâncias e suas relações com atores.

No entanto, essas relações de actância com atores merecem uma leitura cautelosa, pois, observa-se que, no que concerne:

1-ao ato de linguagem publicitário: a marca como Destinador-sujeito, num enunciado produzido por outros destinadores (os diversos profissionais que participaram da concepção-criação da mensagem e do que a sustenta), valoriza o objeto através do benefício que ele fornece para seu público-alvo os Destinatários, teóricos, que representam no nível da recepção o destinador-sujeito da enunciação de decodificação, isto é, os consumidores da mensagem emblemática e publicitária e os consumidores do produto e/ou marca;

2-ao ato de linguagem da marca nos mercados dos produtos em que é aposta: o proprietário jurídico da marca, como actante da enunciação, delegado do enunciador, enuncia as funções de sua marca, qualquer que seja a forma de comunicação escolhida, por meio da produção da enunciação de codificação (emissão) por ele próprio ou por comunicólogos, designers, etc. para os consumidores dos produtos assinados pela marca, consumidores das significações da marca, distribuidores e outras instâncias da sociedade em potencial, que virtualmente representam, como actantes Destinatários, os consumidores dos produtos assinados pela marca e os consumidores das mensagens da marca, destinatários no nível da enunciação de decodificação;

3-ao ato de linguagem da marca, quando o consumidor sígnico a utiliza pelo seu valor como símbolo: esse consumidor enuncia como Destinador a valorização do consumidor utilizador através da marca pelo que ela representa para ele, numa enunciação de codificação cujo sujeito na emissão (destinador) engloba os mercadológos e comunicológos responsáveis pela imagem da marca, o grupo ao qual o consumidor se identifica, a marca através de sua imagem, a sociedade, tendo como Destinatário ele mesmo, os consumidores da marca, os membros de seu grupo societário e a sociedade, enquanto que o sujeito da enunciação de decodificação (destinatário na recepção) é o grupo ao qual esse actante se identifica, os mercadológos e comunicológos responsáveis pela imagem dessa marca, a própria marca e a sociedade;

4-ao ato de convívio sociorelacional da marca quando fabricantes, revendedores e outros skateholders, em sua atuação no contexto em que atuam, remetem a ela ou a têm 
como parceira, numa enunciação de codificação na emissão das mensagens cujo

Destinatário são pessoas físicas ou jurídicas, grupo societários e a sociedade;

5-ao ato ontológico da marca em nossa sociedade: o sujeito do enunciado revela-se ser os fabricantes, revendedores e outros skateholders entre os utilizadores da marca que se identificam, se diferenciam e se relacionam com garantia, expressando as funções da marca, numa enunciação de codificação na emissão das mensagens cujo destinador são as instituições: Direito, Economia, Marketing, Propaganda, História, etc. Esse enunciado tem como Destinatário os consumidores dos produtos (bens, serviços, idéias) com essa marca, sendo o sujeito da enunciação na decodificação a sociedade como um todo.

\section{REFERÊNCIAS BIBLIOGRÁFICAS}

BITTENCOURT, F. Marcas registradas. São Paulo, PUC, 1991. (Dissertação de Mestrado).

GREIMAS, A. J. \& COURTES, J. Dicionário de semiótica. São Paulo, Cultrix, 1983. . Sémiotique, dictionnaire raisonné de la théorie du langage II. Paris, Hachette, 1986.

PAIS, C. T. Conditions sémantico-syntaxiques et sémiotiques de la productivité systémique, lexicale et discursive. 1993. $764 \mathrm{f}$. Tese (Doctorat d'Etat). UFR Etudes Ibériques Linguistique, PARIS IV, Paris.

ZOZZOLI, J. C. J. Da mise en scène da identidade e personalidade da marca: um estudo exploratório do fenômeno marca, para uma contribuição a seu conhecimento. 1994. 327 f. Dissertação (Mestrado em Multimeios). IA, UNICAMP, Campinas.

_. Por uma ontologia da marca. 2002. 342 f. Tese (Doutorado em Ciências da Comunicação). ECA-CRP, USP, São Paulo.

Artigo recebido em 20/3/2009.

Aprovado em 29/4/2009. 